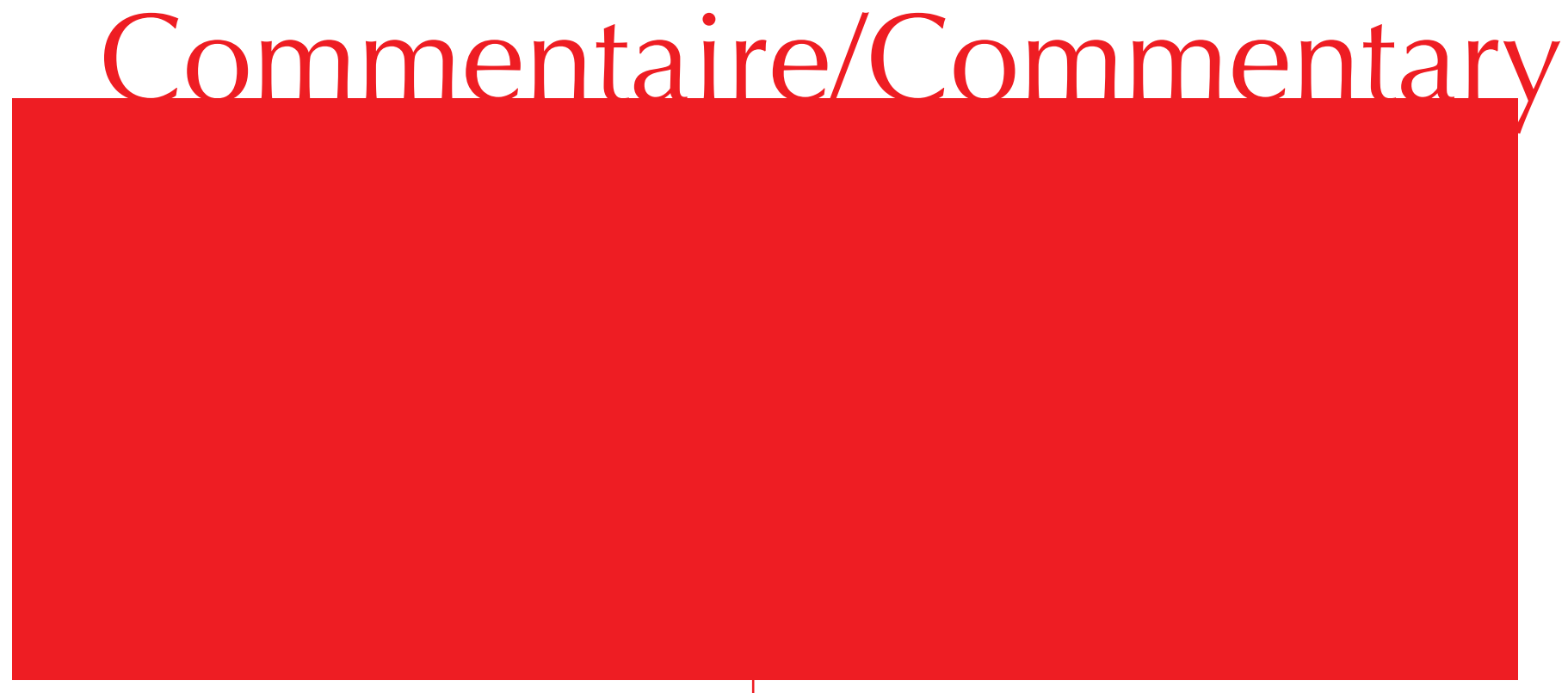

\section{Lessons from the Ottawa 20: Reclaiming the ethics review process to advance academic freedom}

\section{ADRIAN GUTA \& VICTORIA BUNGAY}

\section{Introduction}

We are writing to express our solidarity with 20 members of the University of Ottawa's (henceforth uOttawa) research ethics board (REB) who openly challenged their institution's refusal to support two colleagues in a legal battle to protect the confidentiality of their data. In this commentary we briefly describe the case and reflect on the implications of this collective action for rethinking the role of REBs within the academy. In particular, we argue that REBs should be forums of critical interdisciplinary debate about the relationship between researchers, the academy, knowledge production, and society. Before entering into the larger discussion, it is worth reminding readers of the much maligned status of REBs and ethics review. REBs are often characterized as being secretive bureaucracies overly focused on risk management.[1-3] Certain forms of research, especially qualitative and participatory, have been reportedly subjected to inappropriate standards better suited for biomedical research.[4] As well, the growing infrastructure and resources needed to support ethics review has been likened to a 'research ethics industry.'[3, 5] However, the most troubling critique charges ethics review with being a form of "imperialism" [6] and a threat to academic freedom. [7-9] Haggerty[8] introduced the term "ethics creep" to account for the process whereby ethics review is expanding to colonize aspects of the research process previously outside of its purview. While there are certainly many examples of REBs being paternalistic and risk averse, there are also less discussed examples of REBs that are methodologically savvy and supportive of emerging research approaches. [10-11] Wolf[12] has asked researchers to remember that 
REBs "are not the enemy" but that they are constrained by various requirements that shape their reviews. Guta and colleagues[13] have argued that the so called "ethics creep" is symptomatic of the impact of neoliberal restructuring which has imbued universities with market logic and has turned knowledge into a commodity. Here, the virtues of competition, efficiency, and risk management have replaced other ethical considerations. Yet, ethics review is relatively new and there are still opportunities to improve the system. If researchers feel oppressed and unsupported by ethics review in its current state, they should organize to reclaim it. We now turn our attention to recent events at uOttawa to demonstrate that REBs have the potential to transcend their bureaucratic origins.

\section{The case}

The case in question involves two uOttawa criminology professors who are challenging an attempt by Montreal police to seize a confidential interview transcript believed to belong to a murder suspect. The interview was part of a study conducted by Professors Colette Parent and Chris Bruckert on the experiences of Montreal sex workers. The two researchers in question have filed motions with the Superior Court of Quebec to prevent the police from obtaining these data because of what they argue is "confidentiality privilege." [14] Unfortunately, uOttawa is refusing to assist them in their legal battle, with President Allan Rock having stated that "The University of Ottawa recognizes its role...in safeguarding entrusted information. However, the University does not consider that its role extends to the payment of legal costs if researchers decide to challenge the seizure of research records in the context of criminal proceedings." [15] This is reminiscent of an earlier high profile Canadian case at Simon Fraser University, involving graduate student Russell Ogden, who interviewed people with HIV/AIDS who were seeking assistance to end their lives. In the Ogden case the university refused to defend the researcher and uphold the confidentiality of the data. The REB subsequently imposed a condition of "limited confidentiality" requirements on future research.[16] In the uOttawa case, however, there has been a different response from the REB. Instead of closing ranks against the researchers, 20 members of the uOttawa REB have written to President Rock protesting the administration's refusal to support their colleagues. The letter stated that "The inaction on the part of university officials entrusted with advancing intellectual inquiry is inexcusable" and warned of the "dangerous precedent" being set.[17] While the case will be reviewed in court later this year, and the argument for whether researchers have "confidentiality privilege" will likely be challenged, this case has important implications for how we think about the role of REBs within academic institutions. Here, a group of interdisciplinary scholars representing the Social Sciences \& Humanities Research Ethics Board and Health Sciences \& Science Research Ethics Board have come together in solidarity with their colleagues to protect academic freedom and promote institutional accountability.

\section{The REB as a critical space?}

With the aim of theorizing the uOttawa REB action as a form of critical resistance and truth telling, we turn to Michel Foucault's[18] writings about the relationship between forms of governance and questions of politics and ethics. Foucault's[19,20] conception of ethics started with the relationship of self-to-self (or self-governance), and the process of stylizing oneself as an ethical subject. Foucault may seem an unusual figure to invoke in a discussion of ethics review, for he rejected normative ethics and was interested in larger questions about the relationship between truth, power, and subjectivity. However, recent scholarship in critical bioethics has considered the implications of Foucault's work for resisting prescriptive forms of ethics found in medical relations of power.[21-23] The uOttawa REB members' action has caused us to reflect on Foucault's [24] definition of critique as "the art of voluntary insubordination, that of reflected intractability...[which] insures the desubjugation of the subject in the context of what we could call, in a word, the politics of truth." The uOttawa action represents an important example of resisting the prescribed model of what an REB ought to do, as well as its ostensible role within the academy. This group of scholars have chosen, in their role as REB members, to call attention to the injustice of their institution colluding with law enforcement. This institution, like many universities today, profits from the research being conducted under its name but appears to shirk its responsibility to researchers, participants, and society as a whole. This action further reminds some of us, and may finally prove to others, that REBs are not faceless entities, but are comprised of our peers and colleagues. Many REB members are uncomfortable with aspects of research ethics review and their role as arbiters of what constitutes ethical/ unethical research. Their insider perspectives are especially important for understanding the inner workings and logic of research governance. Yet, too often the collective response is to discredit those who volunteer their time and discount their scholarly expertise. Is it any wonder that REBs struggle to find committed members who are passionate about the role? If research governance has overtaken research ethics, [25] 
then critique is the process of resisting such governance, or in Foucault's[24] terms "the art of not being governed quite so much."

While forms of governance within the academy are ubiquitous, these 20 members of the UOttawa REB are demonstrating a form of ethics that requires them to speak out and challenge what they perceive as injustice within their institution. The identification of injustice further gives us pause regarding Foucault's[18] concept of parrhesia from antiquity, which he described as "the act of telling all (frankness, open-heartedness, plain speaking, speaking openly, speaking freely)." Foucault[26] understood truth telling as an obligatory form of resistance to being governed, saying:

...we can demand of those who govern us a certain truth as to their ultimate aims, the general choices of their tactics, and a number of particular points in their programs: this is the parrhesia (free speech) of the governed, who can and must question those who govern them, in the name of the knowledge, the experience they have, by virtue of being citizens, of what those who govern do, of the meaning of their action, of the decisions they have taken.

Here the members of the uOttawa REB are openly questioning their administration from the position of their shared role on the REB, and demonstrating a commitment to the principles of ethical research set out in Canada's Tri-Council Policy Statement: Ethical Conduct of Research Involving Humans, 2nd edition.[27] While not all REBs are comprised of such scholars, and not all will be willing or able to put themselves at risk within their institutions, we hope the action of the uOttawa REB invites others to consider their own voice in the ethics review process. We see the action of these REB members as the beginnings of rethinking REBs as critical spaces and reclaiming their bureaucratic functions to promote greater critical engagement with ethical questions. For instance, while in this case the action was directed outwards to call attention to uOttawa's refusal to protect confidentiality, such action could also be directed inward to challenge taken-forgranted practices within REBs. The review process represents a microcosm of issues affecting the academy and society. It can unintentionally reproduce forms of oppression and discrimination when certain groups are portrayed as 'at risk' and others not; as competent, or not. Those of us involved in the REB process, on either side of the review, must continue to work towards unpacking the claims made about these imagined others by interrogating our individual and collective values and assumptions. This requires the ability to reflect on one's own role within the system, through the application of what Murray and Holmes[28] have called "critical ethical reflexivity." While their intention was to add a phenomenological understanding of language to bioethical inquiry, we see "critical ethical reflexivity" as relevant for ethics review. We encourage scholars with a range of perspectives to join their REB and to use it as a space to speak out and to challenge all forms of oppression, especially those that reach participants in the form of discriminatory research, but also those that circulate within their institutions to privilege some forms of scholarship over others.

\section{Conclusion}

Foucault[29] famously remarked, "Where there is power, there is resistance." This is evident in the example of 20 members of the uOttawa REB defending their colleagues and standing up against their institution's inaction. We hope this will represent an important first step towards improving relations between researchers and their REBs. Upshur [30] has called on researchers to "Ask not what your REB can do for you; ask what you can do for your REB." We would add that it is important to ask what we, collectively, can do for our REBs, and for our fellow researchers. Such an approach requires working within and across our respective roles as REB members and researchers who submit protocols and to recognize these are one and the same. By collectively resisting the pressure to produce certain kinds of research, and rejecting prescribed notions of objectivity when interacting with participants, we can promote a conception of research ethics within the academy that better reflects our scholarly interests and commitment to preventing research related harms. We believe this aspirational proposition will be achievable if we continuously practice critical ethical reflexivity and remain committed to promoting the virtue of parrhesia within the academy.

\section{References}

1.Ashcroft RE, Pfeffer N. Ethics behind closed doors: Do research ethics committees need secrecy? British medical journal 2001;322(7297):1294-6.

2.O'Reilly M, Dixon-Woods M, Angell E, Ashcroft RE, Bryman A. Doing accountability: a discourse analysis of research ethics committee letters. Sociol Health Illness 2009;31(2):246-61.

3.Allen G. Getting Beyond Form Filling: The Role of Institutional Governance in Human Research Ethics. Journal of Academic Ethics 2008;6(2):105-16.

4.Lincoln YS, Tierney WG. Qualitative Research and Institutional Review Boards. Qualitative Inquiry 
$2004 ; 10(2): 219-34$

5.Ashcroft RE. The new national statement on ethical conduct in research involving humans: A social theoretic perspective. Monash Bioethics Review 1999;18(4 (Ethics Committee Supplement)):14-7.

6.Schrag ZM. Ethical imperialism: institutional review boards and the social sciences, 1965-2009: Johns Hopkins University Press; 2010.

7.Dingwall R. The ethical case against ethical regulation in humanities and social science research. Contemporary Social Science: Journal of the Academy of Social Sciences. 2008;3(1):1-12.

8. Haggerty KD. Ethics Creep: Governing Social Science Research in the Name of Ethics. Qualitative Sociology. 2004 winter;27(4):391-414.

9. Lewis M. New Strategies of Control: Academic Freedom and Research Ethics Boards. Qualitative Inquiry 2008;14(5):68499.

10.Hedgecoe A. Research Ethics Review and the Sociological Research Relationship. Sociology 2008;42(5):873-86.

11.Guta A, Nixon S, Gahagan J, Fielden S. "Walking Along Beside the Researcher": How Canadian REBs/IRBs are Responding to the Needs of Community-based Participatory Research. Journal of Empirical Research on Human Research Ethics. 2012;7(1):15-25.

12.Wolf LE. The research ethics committee is not the enemy: oversight of community-based participatory research. J Empir Res Hum Res Ethics. [Research Support, Non-U.S. Gov't]. 2010;5(4):77-86.

13.Guta A, Nixon S, Wilson MG. Resisting the seduction of "ethics creep": Using Foucault to surface complexity and contradiction in research ethics review. Social Science \& Medicine. 2012.

14.Fieibel A. Police investigators believe $U$ of $O$ professors interviewed accused killer for sex trade study. Fulcrum: The University of Ottawa's independent English-language student newspaper. 2013.

15.uOttawa criminologists go to court to protect research confidentiality [database on the Internet]2013 [cited January]. Available from: http://www.cautbulletin.ca/en_ article.asp?articleid=3574.

16. The Research Confidentiality Controversy at Simon Fraser University [database on the Internet]2000. Available from: http://www.sfu.ca/ palys/Controversy.htm.
17.REB members deplore uOttawa's refusal to defend confidentiality [database on the Internet]2013 [cited January]. Available from: http://www.cautbulletin.ca/en_ article.asp?ArticlelD=3623.

18.Foucault M. The Hermeneutics of the Subject: Lectures at the College de France 1981-1982 Davidson Al, editor. New York: Picador; 2005.

19.Foucault M. The Use of Pleasure: The History of Sexuality - Volume 2. New York: Vintage Books; 1985.

20.Foucault M. The History of Sexuality, Vol. 3: The Care of the Self Vintage books ed. New York: Vintage Books; 1990.

21.Chambon AS, Irving A. "They Give Reason a Responsibility Which It Simply Can't Bear": Ethics, Care of the Self, and Caring Knowledge. Journal of Medical Humanities. 2003;24(3/4):265-78.

22. Murray SJ. Care and the self: biotechnology, reproduction, and the good life. Philosophy, Ethics, and Humanities in Medicine 2007;2(6):1-15.

23. Frank AW, Jones T. Bioethics and the Later Foucault. Journal of Medical Humanities 2003;24(3/4):179-86.

24.Foucault M. What is critique? . In: Lotringer S, Rajchman J, editors. The politics of truth. Los Angeles, CA: Semiotext(e); 2007. p41-82.

25.Sieber JE, Tolich M. Research ethics and research governance. J Empir Res Hum Res Ethics 2012;7(2):1-2.

26.Foucault M. An Aesthetics of Existence In: Kritzman LD, editor. Politics, philosophy, culture: interviews and other writings, 1977-1984 New York: Routledge; 1988. p47-54.

27.Canadian Institutes of Health Research, Natural Sciences and Engineering Research Council of Canada, and Social Sciences and Humanities Research Council of Canada. Tri-Council Policy Statement: Ethical Conduct for Research Involving Humans, December 2010.

28.Murray SJ, Holmes D. Toward a critical ethical reflexivity: phenomenology and language in maurice merleau-ponty. Bioethics 2013;27(6):341-7.

29.Foucault M. The History of Sexuality: An Introduction. New York: Vintage Books; 1978.

30.Upshur REG. Ask not what your REB can do for you; ask what you can do for your REB. Canadian Family Physician 2011;57(10):1113-4. 
Contact Information for Authors:

Adrian Guta, M.S.W., R.S.W., Ph.D.

Carleton University

CIHR Postdoctoral Fellow - Health Services/Population Health HIVIAIDS Research

Faculty of Arts \& Social Sciences

1812 Dunton Tower, 1125 Colonel By Dr,

Ottawa, Ontario, K1S 5B6

Canada

Health Research Methods and Training Facility

Simon Fraser University Vancouver

515 West Hastings Street

HCC 3150

Vancouver, British Columbia V6B $5 K 3$

Canada

Email:Adrian.Guta@Carleton.ca

Victoria Bungay, R.N., Ph.D.

Assistant Professor \& Michael Smith Foundation for Health

Research Scholar

University of British Columbia

School of Nursing 